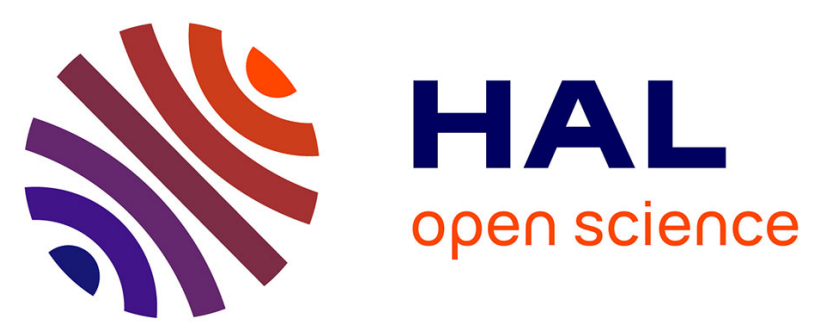

\title{
Nanoscale Imaging of Hydrogen and Sodium in Alteration Layers of Corroded Glass using ToF-SIMS Is an Auxiliary Sputtering Ion Beam Necessary?
}

J. Zhang, Yanyan Zhang, M. Collin, S. Gin, J.J. Neeway, T. Wang, Z. Zhu

\section{- To cite this version:}

J. Zhang, Yanyan Zhang, M. Collin, S. Gin, J.J. Neeway, et al.. Nanoscale Imaging of Hydrogen and Sodium in Alteration Layers of Corroded Glass using ToF-SIMS Is an Auxiliary Sputtering Ion Beam Necessary?. Surface and Interface Analysis, 2018, 51, pp.219-225. 10.1002/sia.6571 . cea-02339746

\section{HAL Id: cea-02339746 \\ https://hal-cea.archives-ouvertes.fr/cea-02339746}

Submitted on 5 Nov 2019

HAL is a multi-disciplinary open access archive for the deposit and dissemination of scientific research documents, whether they are published or not. The documents may come from teaching and research institutions in France or abroad, or from public or private research centers.
L'archive ouverte pluridisciplinaire HAL, est destinée au dépôt et à la diffusion de documents scientifiques de niveau recherche, publiés ou non, émanant des établissements d'enseignement et de recherche français ou étrangers, des laboratoires publics ou privés. 


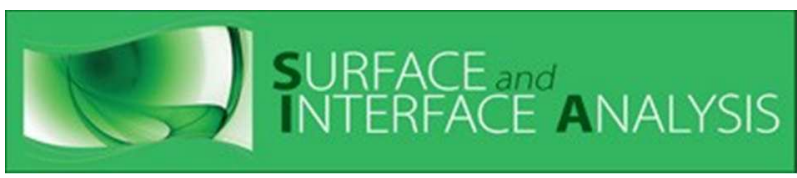

\section{Nanoscale Imaging of Hydrogen and Sodium in Alteration Layers of Corroded Glass using ToF-SIMS: Is an Auxiliary Sputtering Ion Beam Necessary?}

\begin{tabular}{|c|c|}
\hline Journal: & Surface and Interface Analysis \\
\hline Manuscript ID & Draft \\
\hline Wiley - Manuscript type: & Research Article \\
\hline Date Submitted by the Author: & $\mathrm{n} / \mathrm{a}$ \\
\hline Complete List of Authors: & $\begin{array}{l}\text { Zhang, Jiandong; Lanzhou University, Lanzhou, Gansu 730000, PR China, } \\
\text { School of Nuclear Science and Technology, ; Pacific Northwest National } \\
\text { Laboratory, Environmental Molecular Sciences Laboratory } \\
\text { Zhang, Yanyan; Pacific Northwest National Laboratory, Environmental } \\
\text { Molecular Sciences Laboratory; Institute of Chemistry, Chinese Academy of } \\
\text { Sciences, Beijing 100190, P. R. China, Beijing National Laboratory for } \\
\text { Molecular Sciences, National Centre for Mass Spectrometry in Beijing, } \\
\text { COLLIN, Marie; CEA, DEN, DE2D, SEVT, F-30207 Bagnols-sur-Ceze, , DEN, } \\
\text { DE2D, SEVT } \\
\text { Gin, Stéphane; CEA, DEN, DE2D, SEVT, F-30207 Bagnols-sur-Ceze, , DEN, } \\
\text { DE2D, SEVT } \\
\text { Neeway, James; Pacific Northwest National Laboratory, Environmental } \\
\text { Molecular Sciences Laboratory } \\
\text { Wang, Tieshan; Lanzhou university, School of nuclear science and } \\
\text { technology } \\
\text { Zhu, Zihua; Pacific Northwest National Laboratory, Environmental } \\
\text { Molecular Sciences Laboratory }\end{array}$ \\
\hline Keywords: & $\begin{array}{l}\text { Hydrogen imaging, glass corrosion, } \mathrm{H} / \mathrm{Na} \text { interface, ToF-SIMS imaging, } \\
\text { alteration layer, ISG glass }\end{array}$ \\
\hline
\end{tabular}

\section{SCHOLARONE ${ }^{\mathrm{m}}$}

Manuscripts 


\title{
Nanoscale Imaging of Hydrogen and Sodium in Alteration Layers of Corroded Glass using ToF-SIMS: Is an Auxiliary Sputtering Ion Beam \\ Necessary?
}

\author{
Jiandong Zhang ${ }^{1,2}$, Yanyan Zhang ${ }^{2}$, Marie Collin ${ }^{3}$, Stephane Gin $^{3}$, James Neeway ${ }^{4}$, Tieshan Wang ${ }^{1 *}$, \\ Zihua $\mathrm{Zhu}^{2 *}$ \\ 1. School of Nuclear Science and Technology, Lanzhou University, Lanzhou, Gansu 730000, PR China, \\ 2. W. R. Wiley Environmental Molecular Sciences Laboratory, Pacific Northwest National Laboratory, Richland, WA 99354 USA \\ 3. CEA, DEN, DE2D, SEVT, F-30207 Bagnols-sur-Ceze, France \\ 4. Energy and Environment Directorate, Pacific Northwest National Laboratory, Richland, WA 99354, USA
}

*Corresponding authors: zihua.zhu@pnnl.gov; tswang@|zu.edu.cn; 


\begin{abstract}
The hydrogen $(\mathrm{H})$ /sodium $(\mathrm{Na})$ interface is of great interest in glass corrosion research. Time-of-flight secondary ion mass spectrometry (ToF-SIMS) is one of the few techniques that can provide nanoscale $\mathrm{H}$ and $\mathrm{Na}$ imaging simultaneously. However, the optimized condition for ToF-SIMS imaging of $\mathrm{H}$ in glass is still unclear. In $\mathrm{H}$ depth profiling using ToF-SIMS, $\mathrm{H}$ background control is a key, in which an analysis ion beam and a sputtering ion beam work together in an interlaced mode to minimize it. Therefore, it is of great interest to determine if an auxiliary sputtering ion beam is also necessary to control $\mathrm{H}$ background in ToF-SIMS imaging of H. In this study, a $\mathrm{Bi}^{+}$primary ion beam with different auxiliary sputtering beams $\left(\mathrm{Cs}^{+}, \mathrm{O}_{2}^{+}\right.$and $\mathrm{Ar}_{\mathrm{n}}{ }^{+}$) were compared on a corroded International Simple Glass (ISG). It was surprising that the $\mathrm{H} / \mathrm{Na}$ interface could be directly imaged using positive ion imaging without any auxiliary sputtering ion beam under a vacuum of $2-3 \times 10^{-8}$ mbar. The $\mathrm{H}^{+}$background was about $5 \%$ atomic percent on the pristine ISG glass, which was significantly lower than the $\mathrm{H}$ concentration in the alteration layer $(\sim 15 \%)$. Moreover, positive ion imaging could show distributions of other interesting species simultaneously, providing more comprehensive information of the glass corrosion. The $\mathrm{H}^{+}$background could be reduced with an auxiliary $\mathrm{O}_{2}^{+}$sputtering ion beam; however, significant loss of signal intensities was observed. In addition, a higher $\mathrm{H}$ background in ToF-SIMS imaging than that in the depth profiling was observed.
\end{abstract}

Key words: Hydrogen imaging, glass corrosion, H/Na interface, ToF-SIMS imaging, alteration layer, ISG glass 


\section{Introduction}

Nanoscale elemental imaging has been of great importance in glass corrosion research ${ }^{1-4}$. Compared to depth profiling, imaging provides a direct view of the elemental distribution on the corroded glass surface and altered glass/pristine glass interfaces, which is very valuable to understand the complex mechanisms involved in glass corrosion. Corrosion can lead to inhomogeneous alteration layers, rough surfaces and interfaces, which are difficult to distinguish by depth profiling ${ }^{2,5}$. Moreover, some glass particle samples have been used to increase glass surface area and perform accurate rate measurement, and imaging may be the best way to characterize the alteration layers on particle surfaces ${ }^{6,7}$.

Hydrogen $(\mathrm{H})$ and sodium $(\mathrm{Na})$ are both ions of interest in glass corrosion research. $\mathrm{H}^{+}$and $\mathrm{Na}^{+}$not only diffuse as exchanged ions (interdiffusion) in the early stage of glass corrosion but also affect $\mathrm{pH}$ values (hydrolysis) of the solutions during glass corrosion ${ }^{8-11}$. The thickness of alteration layers is usually from tens of nanometers to several micrometers. Therefore, nanoscale spatial resolution is required for accurate imaging of alteration layers. However, very few techniques can perform hydrogen imaging on the nanoscale. For example, transmission electron microscope (TEM) is a widely used imaging tool and can reach a resolution of $\sim 0.1 \mathrm{~nm}$ (or better $)^{8}$, but hydrogen information can’t be directly provided. Scanning electron microscopy (SEM) combined with energy dispersive X-ray spectroscopy (EDX) is also widely used for elemental imaging, but is not efficient for light elements (e.g., $\mathrm{H}, \mathrm{Li}$, and $\mathrm{B}$ ). Atom probe tomography (APT) is a novel method for nanoscale imaging of the alteration layers with 1-3 nm spatial resolution; however, it has a limited field-of-view and sample preparation is complex ${ }^{12-14}$. Time-of-flight secondary ion mass spectrometry (ToF-SIMS) is sensitive to most elements (except noble gases) and has been used for depth profiling of $\mathrm{H} / \mathrm{Na}$ in previous studies ${ }^{2,10,15}$. Moreover, ToF-SIMS can provide elemental distribution with decent spatial resolution $(\sim 100$ 
$\mathrm{nm})^{16,17}$ and has been successfully used in imaging of alternation layers ${ }^{7,13}$. However, there are some tricks in hydrogen analysis using ToF-SIMS ${ }^{18,19}$ and, to our knowledge, hydrogen imaging of alteration layers using ToF-SIMS has not been reported.

Signal intensity is key in SIMS analysis, especially imaging analysis. A challenge for $\mathrm{H}$ analysis using SIMS is that both $\mathrm{H}^{-}$and $\mathrm{H}^{+}$are only moderately sensitive ${ }^{20}$. Because the sensitivity of $\mathrm{H}^{-}$is higher than that of $\mathrm{H}^{+}$, negative ion mode is recommended for $\mathrm{H}$ depth profiling using ToF-SIMS ${ }^{18,19}$. However, $\mathrm{Na}^{-}$signal is very low in negative ion mode, so imaging of $\mathrm{Na}^{-}$is unpractical. Considering that the sensitivity of $\mathrm{H}^{+}$is only one order of magnitude less than that of $\mathrm{H}^{-20}$, it may be a promising idea to use positive ion mode to image $\mathrm{Na}^{+}$and $\mathrm{H}^{+}$ simultaneously. In addition, the residual gases in the SIMS analysis chamber may lead to significant interference during $\mathrm{H}$ analysis. Therefore, the pressure in the SIMS analysis chamber should be kept as low as possible and an interlaced dual beam analysis mode is recommended for $\mathrm{H}$ depth profiling ${ }^{18,19}$. For $\mathrm{H}$ imaging analysis, the above experimental condition may be still needed. Moreover, current ToF-SIMS instruments normally have two possible sputter beams for positive ion analysis, i.e., the traditional $\mathrm{O}_{2}{ }^{+}$beam and the newly developed argon cluster $\left(\mathrm{Ar}_{\mathrm{n}}{ }^{+}\right)$ ion beam. Our previous work ${ }^{21}$ suggests that during dual beam depth profiling analysis, the $\mathrm{Ar}_{\mathrm{n}}{ }^{+}$ sputtering beam leads to less charging and better signal intensity in glass depth profiling analysis. Therefore, it is of interest to investigate which beam is better for $\mathrm{H}$ imaging analysis.

The International Simple Glass (ISG) has been a widely used model glass for reaching a common understanding among different glass corrosion experiments ${ }^{22}$. In this work, a corroded ISG coupon sample was fixed with a supporting glass for imaging of the $\mathrm{H} / \mathrm{Na}$ interfaces using ToF-SIMS. Results obtained using different sputtering beams including $500 \mathrm{eV} \mathrm{O}_{2}^{+}, 1 \mathrm{keV} \mathrm{O}_{2}^{+}$, 
$2 \mathrm{keV} \mathrm{O}_{2}{ }^{+}, 10 \mathrm{keV} \mathrm{Ar}{ }_{\mathrm{n}}^{+}, 20 \mathrm{keV} \mathrm{Ar}_{\mathrm{n}}{ }^{+}$and $2 \mathrm{keV} \mathrm{Cs}^{+}$were compared, and the optimized $\mathrm{H} / \mathrm{Na}$ imaging settings using ToF-SIMS were determined.

\section{Experimental Section}

The nominal composition (mol \%) of ISG glass is: $\mathrm{Si}$ (18.0), B (9.6), Na (7.5), $\mathrm{Al}(2.3), \mathrm{Ca}$ (1.7) and $\mathrm{Zr}(0.5)$ and $\mathrm{O}$ (60.3). The glass was elaborated by MoSci Corporation (Rolla, MO, USA) and then cut into small coupons. A polished coupon of this glass $\left(5.0 \times 5.0 \times 3.0 \mathrm{~mm}^{3}\right)$ was altered for 25 days at $90{ }^{\circ} \mathrm{C}$ in static conditions, in a solution initially saturated with respect to amorphous silica and at a fixed $\mathrm{pH}_{90^{\circ} \mathrm{C}}$ of 7 . These conditions enable the formation of a dense, B and Na-free gel layer (i.e., alteration later) of approximately $2.8 \mu \mathrm{m}$ in thickness on the glass surface. More details could be found in the previous report ${ }^{23}$.

As a commonly used method, the corroded ISG coupon was attached with a supporting ISG glass and then mounted by EpoThin ${ }^{\mathrm{TM}} 2$ epoxy resin. The details are: (1) Attached slides were fixed using a plastic clip and then mounted in the center of a silicone gel mold. (2) Approximately $18 \mathrm{~g}$ of the well-mixed epoxy (2:1 in weight for epoxy resin and epoxy hardener) was poured in the mold. The epoxy was then kept in the fume hood overnight and then transferred into a $50^{\circ} \mathrm{C}$ oven for 3 hours for a further cure. (3) The cured bulk was cut by a diamond saw to expose the cross section. (4) The cutting surface was polished by an ECOMET 6 grinder-polisher. A schematic of the prepared ISG sample was shown in Figure 1. The sample was gold-coated on the back prior to further ToF-SIMS analysis to reduce charging effects. 


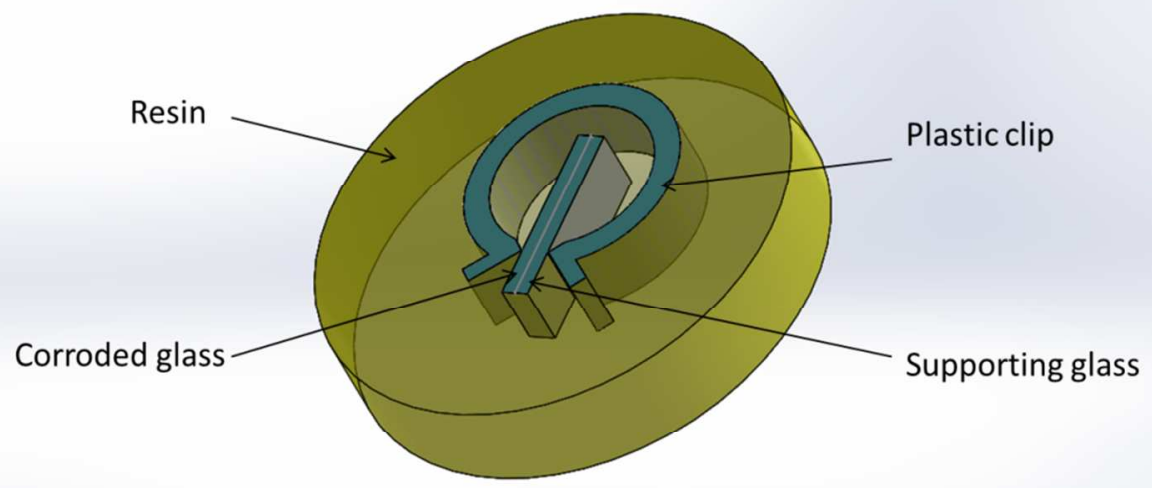

Figure 1. Schematic of the prepared ISG sample

The ToF-SIMS analysis was performed using a TOF.SIMS 5 spectrometer (IONTOF GmbH, Müster, Germany), which was equipped with a $25 \mathrm{keV}$ bismuth (Bi) cluster ion source, a $20 \mathrm{keV}$ $\mathrm{Ar}_{\mathrm{n}}{ }^{+}$and a $2 \mathrm{keV} \mathrm{Cs} / \mathrm{O}_{2}^{+}$sputtering ion sources. Conditions of sputtering beams including 500 $\mathrm{eV} \mathrm{O}_{2}^{+}, 1 \mathrm{keV} \mathrm{O}_{2}^{+}, 2 \mathrm{keV} \mathrm{O}_{2}^{+}, 10 \mathrm{keV} \mathrm{Ar}_{\mathrm{n}}^{+}$and $20 \mathrm{keV} \mathrm{Ar}_{\mathrm{n}}^{+}$with different currents were used as summarized in Table 1. Monatomic bismuth ions $\left(\mathrm{Bi}^{+}\right)$were used as the analysis beam during the experiments ${ }^{19}$. A flood gun was used during all the processes to compensate charging effects. The base pressure of the ToF-SIMS analysis chamber was about $5 \times 10^{-9} \mathrm{mbar}$. Overnight pumping in the introduction chamber was applied before a sample was introduced into the analysis chamber. During depth profiling analysis, a piece of ISG glass without resin fixation was introduced into the analysis chamber and the pressure slightly increased to about $6-7 \times 10^{-9}$ mbar. With $\mathrm{Cs}^{+}$or $\mathrm{Ar}_{\mathrm{n}}{ }^{+}$sputtering, the pressure increased to about $1 \times 10^{-8} \mathrm{mbar}$. When using $\mathrm{O}_{2}^{+}$for sputtering, the pressure increased to about $5 \times 10^{-8} \mathrm{mbar}$ arising from the $\mathrm{O}_{2}$ gas from the $\mathrm{O}_{2}{ }^{+}$sputtering source. For the resin-fixed sample used in imaging analysis, the vacuum pressure of the analysis chamber was about $2-3 \times 10^{-8}$ mbar and did not change during single $\mathrm{Bi}^{+}$beam imaging analysis. However, the pressure was about 7-8 $\times 10^{-8}$ mbar during $\mathrm{O}_{2}{ }^{+}$beam-auxiliary imaging analysis. 
Table $1 \mathrm{O}_{2}^{+}$and $\mathrm{Ar}_{n}^{+}$sources as sputtering beams with different currents.

\begin{tabular}{ccccccccccc}
\hline Sputter beam & \multicolumn{2}{c}{$\begin{array}{c}500 \mathrm{eV} \mathrm{O}_{2}^{+} \\
\text {beam }\end{array}$} & \multicolumn{2}{c}{$\begin{array}{c}\mathrm{keV} \mathrm{O}_{2}^{+} \\
\text {beam }\end{array}$} & \multicolumn{2}{c}{$\begin{array}{c}2 \mathrm{keV} \mathrm{O}_{2}^{+} \\
\text {beam }\end{array}$} & $\begin{array}{c}10 \mathrm{keV} \mathrm{Ar}_{\mathrm{n}}^{+} \\
\text {beam }\end{array}$ & $\begin{array}{c}20 \mathrm{keV}^{+} \mathrm{Ar}_{\mathrm{n}}^{+} \\
\text {beam }\end{array}$ \\
\hline \multirow{2}{*}{ Current ratio } & $\begin{array}{c}\text { Current } \\
(\mathrm{nA})\end{array}$ & $\begin{array}{c}\text { Current } \\
\text { density } \\
\left(\mathrm{A} / \mathrm{m}^{2}\right)\end{array}$ & $\begin{array}{c}\text { Current } \\
(\mathrm{nA})\end{array}$ & $\begin{array}{c}\text { Current } \\
\text { density } \\
\left(\mathrm{A} / \mathrm{m}^{2}\right)\end{array}$ & $\begin{array}{c}\text { Current } \\
(\mathrm{nA})\end{array}$ & $\begin{array}{c}\text { Current } \\
\text { density } \\
\left(\mathrm{A} / \mathrm{m}^{2}\right)\end{array}$ & $\begin{array}{c}\text { Current } \\
(\mathrm{nA})\end{array}$ & $\begin{array}{c}\text { Current } \\
\text { density } \\
\left(\mathrm{A} / \mathrm{m}^{2}\right)\end{array}$ & $\begin{array}{c}\text { Current } \\
(\mathrm{nA})\end{array}$ & $\begin{array}{c}\text { Current } \\
\text { density } \\
\left(\mathrm{A} / \mathrm{m}^{2}\right)\end{array}$ \\
\hline $100 \%$ & 79.6 & 0.884 & 173.8 & 1.931 & 434.1 & 4.823 & 6.75 & 0.169 & 8.15 & 0.204 \\
$50 \%$ & 39.6 & 0.44 & 87.1 & 0.967 & 217.1 & 2.412 & 3.33 & 0.083 & 4.09 & 0.102 \\
$20 \%$ & 15.7 & 0.174 & 34.8 & 0.387 & 86.7 & 0.963 & 1.36 & 0.034 & 1.62 & 0.041 \\
$10 \%$ & 7.8 & 0.086 & 17.4 & 0.193 & 43.3 & 0.481 & 0.67 & 0.017 & 0.81 & 0.02 \\
$5 \%$ & 3.9 & 0.044 & 8.7 & 0.097 & 21.6 & 0.24 & 0.34 & 0.009 & 0.4 & 0.01 \\
$2 \%$ & 1.6 & 0.018 & 3.5 & 0.039 & 8.6 & 0.096 & 0.14 & 0.004 & 0.17 & 0.004 \\
$1 \%$ & 0.7 & 0.008 & 1.7 & 0.019 & 4.5 & 0.05 & 0.07 & 0.002 & 0.08 & 0.002 \\
$0 \%$ & 0 & 0 & 0 & 0 & 0 & 0 & 0 & 0 & 0 & 0 \\
\hline
\end{tabular}

Depth profiling was used to investigate the efficiency of secondary ion yields on a blank ISG coupon. The raster sizes were $300 \times 300 \mu \mathrm{m}^{2}$ for $\mathrm{Cs}^{+} / \mathrm{O}_{2}{ }^{+}$and $200 \times 200 \mu \mathrm{m}^{2}$ for $\mathrm{Ar}_{\mathrm{n}}{ }^{+}$sputtering beams. A $25 \mathrm{keV} \mathrm{Bi}^{+}$beam was used as the analysis beam at $10 \mathrm{kHz}$ frequency. The analysis area was $100 \times 100 \mu \mathrm{m}^{2}$ or $50 \times 50 \mu \mathrm{m}^{2}$ in the center of the sputtering craters by $\mathrm{Cs}^{+} / \mathrm{O}_{2}^{+}$and $\mathrm{Ar}_{\mathrm{n}}{ }^{+}$, respectively. The current of $\mathrm{Bi}^{+}$was around $1.0 \mathrm{pA}$. The crater depths were measured by a stylus profilometer and a constant sputtering rate was assumed for each crater. For imaging, the sputter beam setting was almost the same as that in the depth profiling analysis (but with various currents). The analysis beam (pulsed $\mathrm{Bi}^{+}$beam) was rastered over a $30 \times 30 \mu \mathrm{m}^{2}$ area in the center of sputtering area at a $25 \mathrm{kHz}$ frequency. The beam size was tuned to be $\sim 200 \mathrm{~nm}$ in diameter (using a 1000 mesh $\mathrm{Cu}$ grid reference sample) with a current of $0.5 \mathrm{pA}$. All ion images were $256 \times 256$ pixels with a collection time of about $1000 \mathrm{~s}$. The imaging locations were selected on the interfaces between the corroded glass and the supporting glass. An un-corroded (blank) ISG glass was also analyzed for comparison.

The $2 \mathrm{keV} \mathrm{Cs}{ }^{+}$depth profiling data was used to estimate the $\mathrm{H}$ concentration in the alteration layer based on the normalized $\mathrm{H}^{-} / 30 \mathrm{Si}^{-}$intensity and related $\mathrm{RSF}$ (relative sensitivity factor) 
values obtained from the reference ${ }^{18}$. The average $H$ concentration in the alteration layer was found to be $15 \%$ (atomic ratio).

\section{Results and discussion}

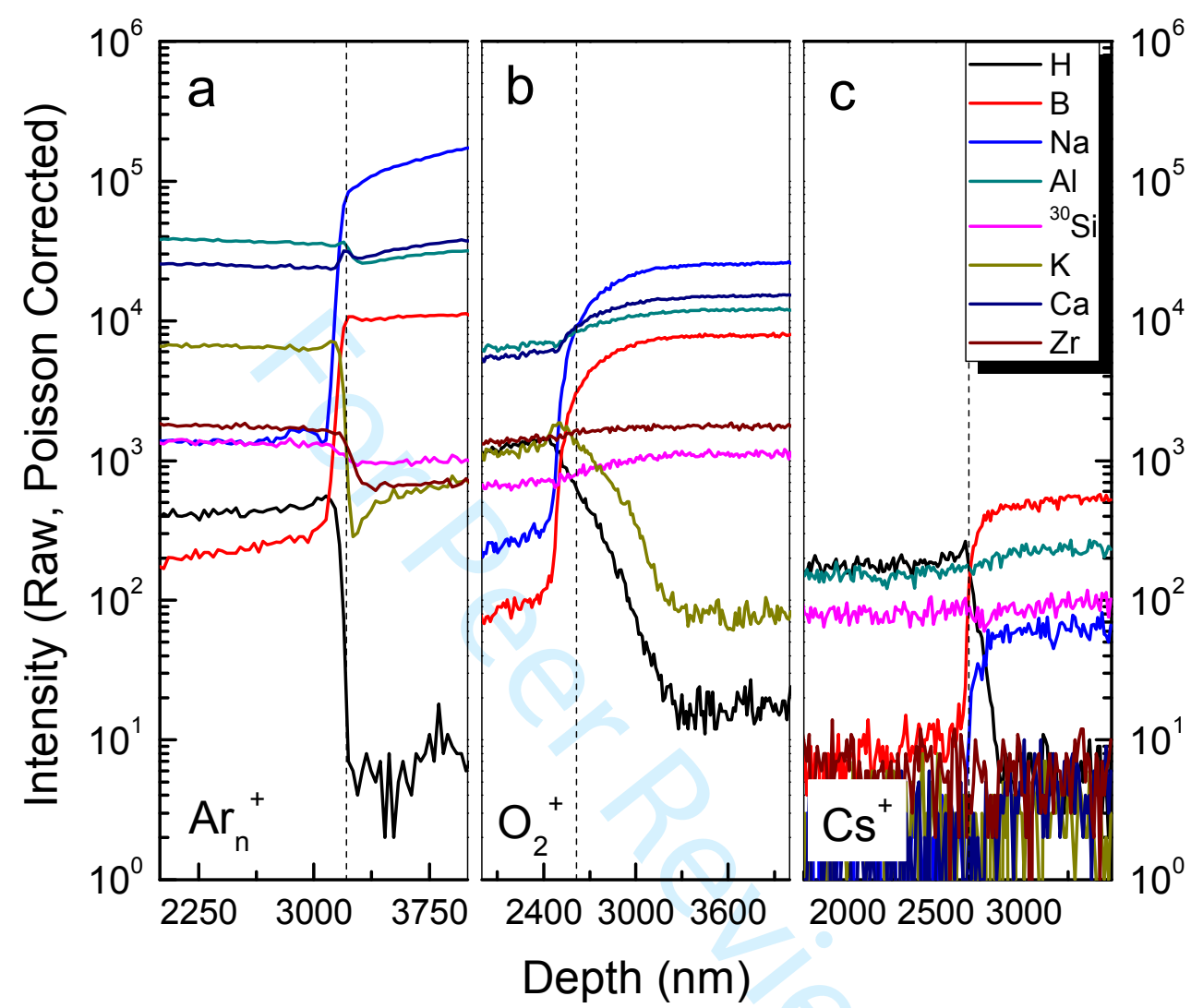

Figure 2. Depth profiles of several ion species of interest on corroded ISG glass in positive (with $\mathrm{Ar}_{\mathrm{n}}^{+}$, $\mathrm{O}_{2}{ }^{+}$sputtering) and negative (with $\mathrm{Cs}^{+}$sputtering) ion modes: sputtering beams were $20 \mathrm{keV} \mathrm{Ar}_{\mathrm{n}}^{+}$(a), 2 $\mathrm{keV} \mathrm{O}_{2}^{+}$(b) and $2 \mathrm{keV} \mathrm{Cs}^{+}$(c) with the current ratio of $100 \%$; analysis beam was $25 \mathrm{keV} \mathrm{Bi}^{+}$. The dashed lines refer to the alteration layer-pristine glass interface. Common settings with reasonable sputtering rate and depth resolution in ToF-SIMS analysis were used. The ion intensities were all Poisson-corrected for dead-time correction during the analysis. The measured depths of the alteration front varied from 2700 $\mathrm{nm}$ to $3200 \mathrm{~nm}$ in different analysis areas, possibly due to an inhomogeneous thickness of the altered layers as depth profiling analysis using the above sputtering beams were conducted at different locations of the same sample.

Signal intensity is the key factor for image quality. Generally, the higher the signal intensity, the better the image quality is. As mentioned before, residual gases result in some background for SIMS analysis of $\mathrm{H}$, so a dual beam depth profiling strategy with an interlaced analysis mode 
is recommended to reduce it. Figure 2 shows the depth profiles of several species of interest with $\mathrm{Ar}_{\mathrm{n}}{ }^{+}, \mathrm{O}_{2}{ }^{+}$and $\mathrm{Cs}^{+}$as sputtering beams. It should be noted that the thickness of ISG coupon was about $3.0 \mathrm{~mm}$ and this situation resulted in very serious charging effects when using $\mathrm{Cs}^{+}$ sputtering beam and, thus, the effective signal intensity was low. We can see the $\mathrm{H}^{-}$signal with $\mathrm{Cs}^{+}$sputtering was much lower than the $\mathrm{H}^{+}$signal from either $\mathrm{Ar}_{n}^{+}$sputtering or $\mathrm{O}_{2}^{+}$sputtering. More seriously, the signal intensities of metal ions when using $\mathrm{Cs}^{+}$sputtering, such as $\mathrm{Na}^{-}, \mathrm{K}^{-}$, $\mathrm{Ca}^{-}$and $\mathrm{Zr}^{-}$, were much weaker than the corresponding $\mathrm{Na}^{+}, \mathrm{K}^{+}, \mathrm{Ca}^{+}$and $\mathrm{Zr}^{+}$signals when using $\mathrm{Ar}_{\mathrm{n}}^{+}$or $\mathrm{O}_{2}^{+}$beam. The above observations suggest that $\mathrm{O}_{2}^{+}$and $\mathrm{Ar}_{\mathrm{n}}^{+}$sputtering instead of $\mathrm{Cs}^{+}$ sputtering should be recommended for $\mathrm{H} / \mathrm{Na}$ imaging analysis.

Our $2 \mathrm{keV} \mathrm{Cs}^{+}$depth profiling data suggest that the $\mathrm{H}$ concentration in the alteration layer is about $15 \%$. This result is less than that from the bulk analysis $(\sim 27.6 \%)^{23}$. A possible reason is that SIMS is a high vacuum technique, and some less stable water molecules can escape from the sample before or during SIMS analysis.

It should be noted that the requirement of imaging mode is different from that in depth profiling mode. Generally speaking, in depth profiling, we hope the total analysis time can be as short as possible so we use high sputtering current values to obtain fast sputtering rate. However, for imaging analysis in this work, the sputtering beam is applied only to reduce the $\mathrm{H}$ background, so we hope the currents can be as low as possible. Therefore, we varied the current density of $\mathrm{O}_{2}{ }^{+}$or $\mathrm{Ar}_{\mathrm{n}}{ }^{+}$beam at the sputtering interface, and monitored the detected $\mathrm{H}$ background signal on an un-corroded (blank) ISG sample in an interlaced mode of depth profiling. The results are shown in Figure 3. 

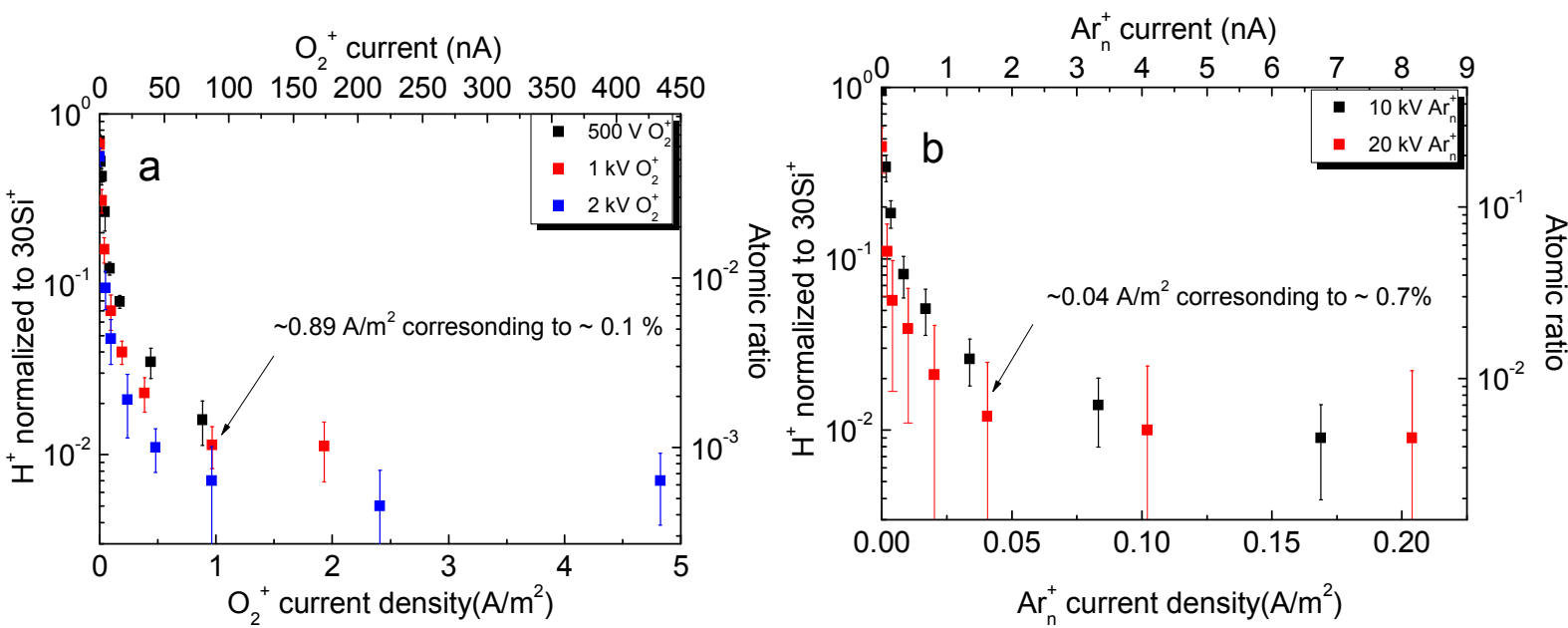

Figure 3. Normalized background $\mathrm{H}^{+}$noise intensities and corresponding $\mathrm{H}$ concentrations as a function of the current density of $\mathrm{O}_{2}^{+}$(a) and $\mathrm{Ar}_{\mathrm{n}}^{+}$(b) in an interlaced mode of depth profiling. Left Y-axis represents the normalized $\mathrm{H}^{+}$intensity and right $\mathrm{Y}$-axis represents the corresponding $\mathrm{H}$ concentration. The lowest $\mathrm{H}$ noise level with $\mathrm{O}_{2}^{+}$sputtering is about $\sim 7 \times 10^{-4}$ (atomic ratio), and the lowest $\mathrm{H}$ noise level with $\mathrm{Ar}_{\mathrm{n}}^{+}$sputtering is about $1 \times 10^{-3}$ (atomic ratio). The estimated concentrations of $\mathrm{H}$ were calculated based on the normalized $\mathrm{H}^{+} /{ }^{30} \mathrm{Si}^{+}$intensity here and the corresponding normalized $\mathrm{H}^{+} /{ }^{30} \mathrm{Si}^{+}$intensity in the alteration layer where $15 \%$ atomic $\mathrm{H}$ was determined.

As shown in Figure $3 \mathrm{a}$, the $\mathrm{H}^{+}$noise level with $\mathrm{O}_{2}{ }^{+}$is $\sim 0.1 \%$ (atomic ratio), and the noise level seems relatively stable if the sputtering current density is larger than $\sim 0.89 \mathrm{~A} / \mathrm{m}^{2}$. As a comparison, the background noise level for $\mathrm{Ar}_{\mathrm{n}}{ }^{+}$sputtering is around $1.0 \%$ (atomic ratio) and it becomes relatively stable when the beam current density is higher than $\sim 0.04 \mathrm{~A} / \mathrm{m}^{2}$. Because we hope the sputter current is as low as possible, a $0.89 \mathrm{~A} / \mathrm{m}^{2}$ for $\mathrm{O}_{2}^{+}$beam or $0.04 \mathrm{~A} / \mathrm{m}^{2}$ for $\mathrm{Ar}_{\mathrm{n}}{ }^{+}$ beam is recommended for $\mathrm{H}$ imaging analysis. 

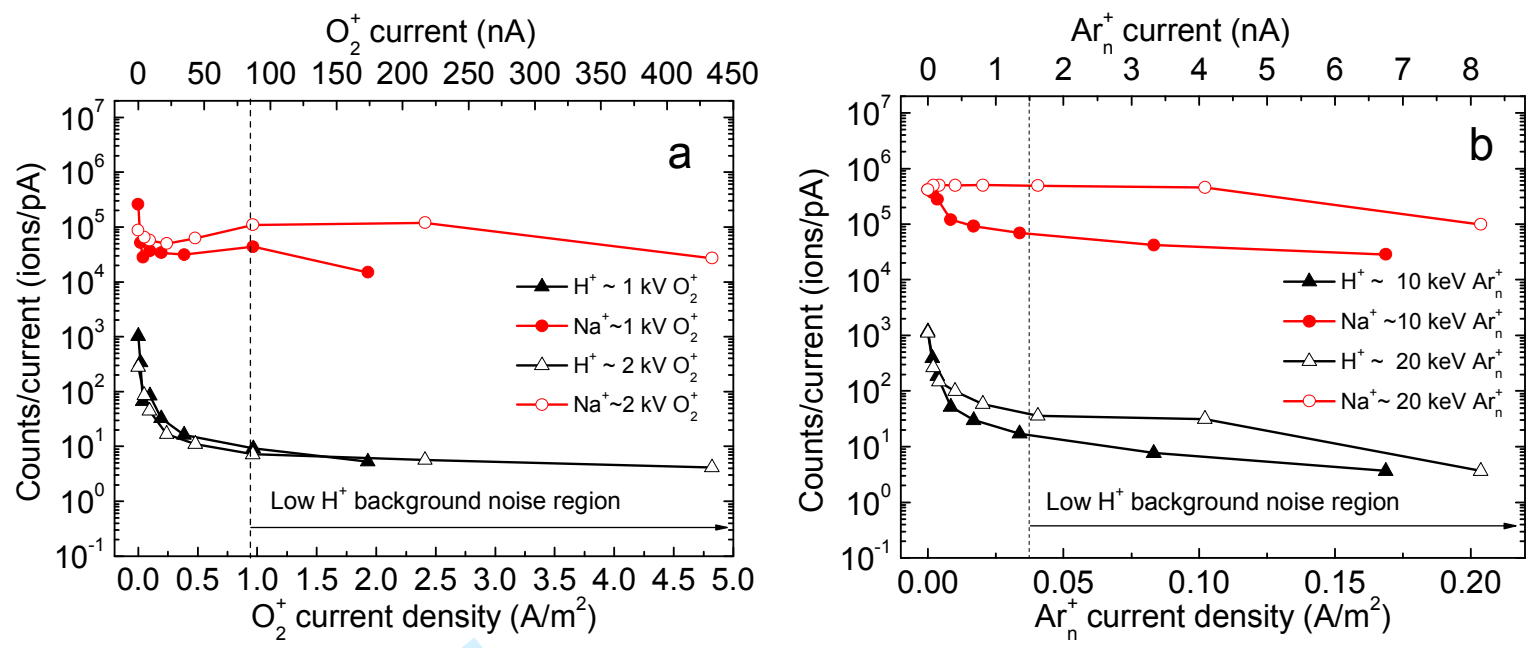

Figure 4. Secondary ion yields of $\mathrm{H}^{+}$and $\mathrm{Na}^{+}$ions on the blank ISG as a function of the current and current density in an interlaced mode depth profiling. Analysis beam was $\mathrm{Bi}^{+}$and the sputtering beams were $\mathrm{O}_{2}^{+}$(a) and $\mathrm{Ar}_{\mathrm{n}}^{+}(\mathrm{b})$.

Simultaneously imaging of $\mathrm{H} / \mathrm{Na}$ is the key in this work. Therefore, $\mathrm{Na}^{+}$signal intensity is also of great interest. The relationship between the $\mathrm{Na}^{+}$signal intensity and the sputtering current density of $\mathrm{O}_{2}^{+}$beam is shown in Figure 4a. We observed a significant decrease in $\mathrm{Na}^{+}$signal intensity with a slight increase of current density and the signal rapidly reached a relatively stable value with further increasing of the beam current density. Therefore, we can only focus on $\mathrm{H}^{+}$signal when choosing the optimal sputtering current for $\mathrm{H} / \mathrm{Na}$ imaging. The secondary ion yields of $\mathrm{H}^{+}$and $\mathrm{Na}^{+}$using $\mathrm{Ar}_{\mathrm{n}}{ }^{+}$are also shown in Figure $4 \mathrm{~b}$. Compared to the $\mathrm{Ar}_{\mathrm{n}}{ }^{+}$beam, the $\mathrm{O}_{2}^{+}$sputtering beam provided less but still very high yield of $\mathrm{Na}^{+}$. Considering the background of $\mathrm{H}^{+}$signal with $\mathrm{Ar}_{\mathrm{n}}{ }^{+}$beam was considerably higher (as shown in Figure 3 ), $1 \mathrm{keV} \mathrm{O}_{2}^{+}$beam with a current density of $0.89 \mathrm{~A} / \mathrm{m}^{2}\left(\sim 80 \mathrm{nA}\right.$ over $\left.300 \times 300 \mu \mathrm{m}^{2}\right)$ is the best choice for imaging. 

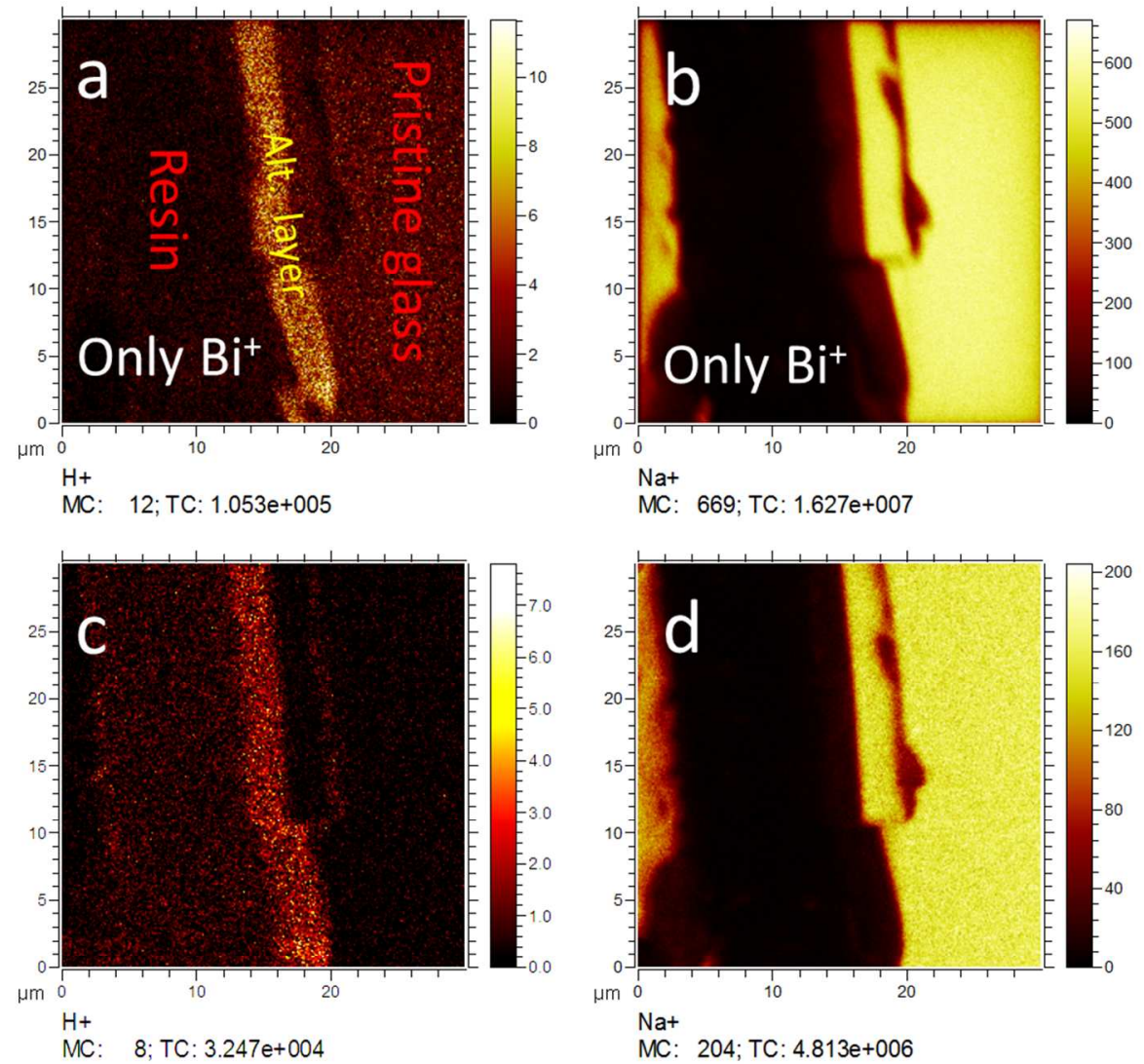

Figure 5. ToF-SIMS imaging of $\mathrm{H}^{+}$and $\mathrm{Na}^{+}$ions using only $\mathrm{Bi}^{+}(\mathrm{a}, \mathrm{b})$ and using $\mathrm{Bi}^{+}$with $1 \mathrm{keV} \mathrm{O}_{2}^{+}$beam at a current density of $0.89 \mathrm{~A} / \mathrm{m}^{2}$, interlaced mode (c, d). The locations of resin, pristine glass and alteration layer were indicated in a. Part of the attached glass was also shown on the left edge of the images. Note that the glass surface is broken beneath the alteration layer; this phenomenon usually occurs during the sample preparation.

ToF-SIMS imaging of $\mathrm{H} / \mathrm{Na}$ using $\mathrm{Bi}^{+}$without (Figures $5 \mathrm{a}$ and $5 \mathrm{~b}$ ) and with (Figures $5 \mathrm{c}$ and 5d) $\mathrm{O}_{2}{ }^{+}$beams are compared. With only $\mathrm{Bi}^{+}, \mathrm{H}^{+}$in the alteration layer was presented with a good intensity (Figure 5a). However, $\mathrm{H}^{+}$distribution was also obviously observed in the pristine glass. The ratio of $\mathrm{H}^{+}$in the alteration layer to the pristine glass was $\sim 3: 1$, indicating a $\sim 5 \%$ (atomic ratio) $\mathrm{H}$ background in the pristine glass. The results using $\mathrm{Bi}^{+}$with a $1.0 \mathrm{keV} \mathrm{O}_{2}{ }^{+}$sputtering beam are shown in Figure 5c and 5d. It is not surprising that the $\mathrm{H}^{+}$intensities decreased (Figure 5c) as compared to that with only $\mathrm{Bi}^{+}$(Figure 5a), but the $\mathrm{H}$ background in the pristine glass was controlled to a much lower level. The ratio of $\mathrm{H}^{+}$in the alteration layer to the pristine glass was 
$8: 1$, indicating a lower $\mathrm{H}$ background of $\sim 1.9 \%$ (atomic ratio) in the pristine glass. However, this is still significantly higher than the value $(\sim 0.1 \%)$ in the corresponding depth profiling analysis (Figure 3a). This observation may be attributed to two possible reasons. Firstly, the sample fixed in resin used in imaging analysis degassed in the vacuum to degrade vacuum quality (as shown in the Experiment session), leading to increasing of $\mathrm{H}$ background. Secondly, less $\mathrm{H}^{+}$signal can be collected from the interesting alteration layer (in depth profiling mode, $100 \%$ of the analysis area is interesting location; as a comparison, only a small amount of area is the alteration layer in imaging mode).
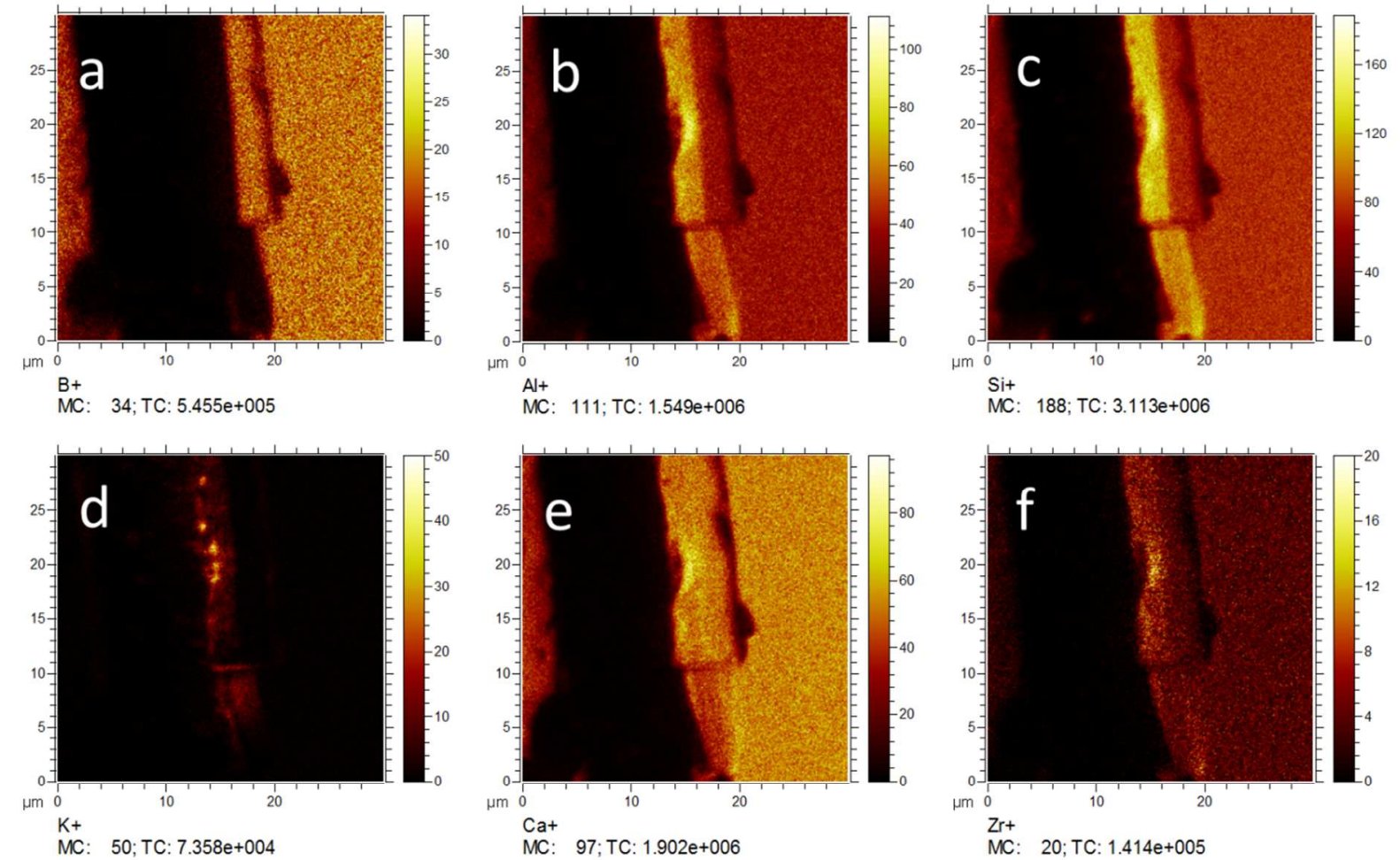

Figure 6. ToF-SIMS images of (a) $\mathrm{B}^{+}$, (b) $\mathrm{Al}^{+}$, (c) $\mathrm{Si}^{+}$, (d) $\mathrm{K}^{+}$, (e) $\mathrm{Ca}^{+}$and (f) $\mathrm{Zr}^{+}$ions. These images were collected simultaneously with those in Figures $5 \mathrm{c}$ and $5 \mathrm{~d}$ using a $1 \mathrm{keV} \mathrm{O}_{2}{ }^{+}$auxiliary sputtering beam at a current density of $0.89 \mathrm{~A} / \mathrm{m}^{2}$.

A unique advantage of ToF-SIMS is that full mass spectrum can be collected and other interesting ion images can be obtained simultaneously. For example, in the positive ion mode, not only $\mathrm{H}^{+}$and $\mathrm{Na}^{+}$but also other interesting ions $\left(\mathrm{B}^{+}, \mathrm{Al}^{+}, \mathrm{Si}^{+}, \mathrm{K}^{+}, \mathrm{Ca}^{+}\right.$and $\left.\mathrm{Zr}^{+}\right)$can be 
simultaneously detected. Figure 6 shows the varied behavior of different elements during glass corrosion. For example, Al, $\mathrm{Si}, \mathrm{Ca}$ and $\mathrm{Zr}$ stay in alteration layer; however, $\mathrm{B}$ is almost totally dissolved. K, an exogenous element, was supplied to the leaching solution by the $\mathrm{pH}$-electrode, which was used to monitor the $\mathrm{pH}$ and then adjust it to the target value. These behaviors are consistent with the observations in depth profiling analysis, as well as in solution analysis reported previously ${ }^{23}$.

It should be noted almost all signal intensities decreased after using an auxiliary $\mathrm{O}_{2}^{+}$ sputtering beam. For example, the $\mathrm{Na}^{+}$intensity was decreased to $\sim 1 / 3$ (Figure $5 \mathrm{~b}$ ) compared to that without $\mathrm{O}_{2}^{+}$(Figure 5d). However, because sensitivities of all other ions of interest are much higher than that of $\mathrm{H}^{+}$, such a signal decrease has limited effects on the overall image quality.

In Figures 5 and 6, the alteration layer was observed partly detached from the sample surface. Such a structure can be easily characterized using ToF-SIMS imaging, but it is unachievable to be reflected by SIMS depth profiling. It has been well known that the formation of alteration layers can change the stress force in the alteration layer and at the alteration layer-pristine glass interface, leading to detachment of sample surface, usually during the sample preparation ${ }^{2}$. However, the depth at which the sample detaches is not the alteration layer-pristine glass interface, but a few microns deeper, suggesting the alteration layer-pristine glass interface may not be mechanically weak.

Our previous work showed that the $\mathrm{H}$ background during SIMS depth profiling is roughly proportional to the vacuum of the analysis chamber ${ }^{18}$. Therefore, it is possible to further reduce $\mathrm{H}$ background in ToF-SIMS imaging of $\mathrm{H}$ by improving the vacuum. In this work, because the glass sample was immobilized in a resin block, the pressure in the analysis chamber was about 2$3 \times 10^{-8}$ mbar. As a comparison, the pressure was about $6-7 \times 10^{-9}$ mbar when only ISG glass 
sample was used. Therefore, it might be possible to reduce the volume of resin in the sample to improve vacuum. For example, using a wire saw to cut a thin piece (e.g., $0.3 \mathrm{~mm}$ ) of the sample and attaching it to a silicon substrate may be a feasible way. In addition, baking the analysis chamber before analysis might also help reduce the base pressure, and $7 \times 10^{-10}$ mbar was achievable in our previous work ${ }^{18}$. If so, $\mathrm{H}$ background could be reduced by at least one order of magnitude, and less than $0.5 \% \mathrm{H}$ background can be expected in ToF-SIMS positive ion imaging of glass samples using a single analysis ion beam.

\section{Conclusion}

In this work, nanoscale $\mathrm{H} / \mathrm{Na}$ imaging of ISG glass alteration layers was realized by ToFSIMS. It is surprising to observe that nanoscale $\mathrm{H} / \mathrm{Na}$ imaging can be done using only a $25 \mathrm{keV}$ $\mathrm{Bi}^{+}$analysis beam without any auxiliary sputtering ion beam, because the $\mathrm{H}$ background on the pristine glass was found to be only $\sim 5 \%$ atomic percent under a vacuum of $2-3 \times 10^{-8}$ mbar, which is much lower than the $\mathrm{H}$ concentration in the alteration layer of about $15 \%$ atomic percent. Besides, if using an auxiliary $1 \mathrm{keV} \mathrm{O}_{2}{ }^{+}$sputtering beam with a current density of $\sim 0.89$ $\mathrm{A} / \mathrm{m}^{2}$ in imaging, the $\mathrm{H}$ background noise was observed to be reduced on pristine ISG glass. However, the $\mathrm{H}$ background in imaging was significantly higher than that in the depth profiling mode with the same sputtering beam (e.g., $\sim 1.9 \% \mathrm{H}$ background in imaging mode versus $\sim 0.1 \%$ in depth profiling mode with a $1 \mathrm{keV} 0.89 \mathrm{~A} / \mathrm{m}^{2} \mathrm{O}_{2}{ }^{+}$sputtering beam), possibly due to relatively low signal intensity in the imaging mode. Moreover, it has been known that the $\mathrm{H}$ background is roughly proportional to the vacuum of the analysis chamber during SIMS analysis ${ }^{18}$. Therefore, it is possible to further reduce $\mathrm{H}$ background by improving vacuum. With proper sample preparation (e.g., reducing amount of resin as less as possible) and baking of vacuum chamber, 
better than $0.5 \% \mathrm{H}$ background in ToF-SIMS positive ion imaging of glass samples using a single analysis ion beam can be expected.

\section{Acknowledgements}

This work was performed at the Environmental Molecular Sciences Laboratory, a national scientific user facility located at Pacific Northwest National Laboratory (PNNL), and sponsored by the Department of Energy's (DOE) Office of Biological and Environmental Research. It is also supported by the National Natural Science Foundation of China (No. 11505085). We would also like to thank Jungang Wang (PNNL) for his helpful discussions.

\section{References}

1. Geisler T, Nagel T, Kilburn MR, et al. The mechanism of borosilicate glass corrosion revisited. Geochimica Et Cosmochimica Acta. 2015;158:112-129.

2. Gin $S$, Jollivet $P$, Fournier $M$, et al. The fate of silicon during glass corrosion under alkaline conditions: A mechanistic and kinetic study with the International Simple Glass. Geochimica Et Cosmochimica Acta. 2015;151:68-85.

3. Ciccotti M. Stress-corrosion mechanisms in silicate glasses. Journal of Physics D Applied Physics. 2009;42(21):214006-214023(214018).

4. Gin S, Guittonneau C, Godon N, et al. Nuclear Glass Durability: New Insight into Alteration Layer Properties. Journal of Physical Chemistry C. 2011;115(38):18696-18706.

5. Gin S, Jollivet P, Tribet M, Peuget S, Schuller S. Radionuclides containment in nuclear glasses: an overview. Radiochimica Acta. Vol 1052017:927.

6. Abraitis PK, Mcgrail BP, Trivedi DP, Livens FR, Vaughan DJ. Single-pass flow-through experiments on a simulated waste glass in alkaline media at $40^{\circ} \mathrm{C}$. : I. Experiments conducted at variable solution flow rate to glass surface area ratio. Journal of Nuclear Materials. 2000;280(2):196-205.

7. Zhang J, Neeway JJ, Zhang Y, et al. Nanoscale imaging of alteration layers of corroded international simple glass particles using ToF-SIMS. Nuclear Instruments and Methods in Physics Research Section B: Beam Interactions with Materials and Atoms. 2017;404:4551.

8. Bunker BC. Molecular mechanisms for corrosion of silica and silicate glasses $\hat{z}$. Journal of Non-Crystalline Solids. 1994;179(11):300-308.

9. Doremus RH. Interdiffusion of hydrogen and alkali ions in a glass surface. Journal of NonCrystalline Solids. 1975;19:137-144.

10. Neeway JJ, Kerisit SN, Liu J, et al. Ion-Exchange Interdiffusion Model with Potential Application to Long-Term Nuclear Waste Glass Performance. Journal of Physical Chemistry C. 2016;120(17). 
11. Vienna JD, Ryan JV, Gin S, Inagaki Y. Current Understanding and Remaining Challenges in Modeling Long-Term Degradation of Borosilicate Nuclear Waste Glasses. International Journal of Applied Glass Science. 2013;4(4):283-294.

12. Gin S, Ryan JV, Schreiber DK, Neeway J, Cabi, Eacute M. Contribution of atom-probe tomography to a better understanding of glass alteration mechanisms: application to a nuclear glass specimen altered 25 years in a granitic environment. Chemical Geology. 2013;349(4):99-109.

13. Wang Z, Liu J, Zhou Y, et al. Nanoscale imaging of Li and B in nuclear waste glass, a comparison of ToF - SIMS, NanoSIMS, and APT. Surface and Interface Analysis. 2016;48(13):1392-1401.

14. Gin S, Jollivet P, Barba Rossa G, et al. Atom-Probe Tomography, TEM and ToF-SIMS study of borosilicate glass alteration rim: A multiscale approach to investigating rate-limiting mechanisms. Geochimica et Cosmochimica Acta. 2017;202:57-76.

15. Valle N, Verney-Carron A, Sterpenich J, Libourel G, Deloule E, Jollivet P. Elemental and isotopic ( $29 \mathrm{Si}$ and $18 \mathrm{O}$ ) tracing of glass alteration mechanisms. Geochimica Et Cosmochimica Acta. 2010;74(12):3412-3431.

16. Briggs D, Hearn MJ, Fletcher IW, Waugh AR, Mcintosh BJ. Charge compensation and high - resolution TOFSIMS imaging of insulating materials. Surface \& Interface Analysis. 1990;15(1):62 - 65.

17. Barnes TJ, Kempson IM, Prestidge CA. Surface analysis for compositional, chemical and structural imaging in pharmaceutics with mass spectrometry: A ToF-SIMS perspective. International Journal of Pharmaceutics. 2011;417(1):61-69.

18. Zhu Z, Shutthanandan V, Engelhard M. An investigation of hydrogen depth profiling using ToF-SIMS. Surface \& Interface Analysis. 2012;44(2):232-237.

19. Zhu Z, Shutthanandan V. Are cluster ion analysis beams good choices for hydrogen depth profiling using time-of-flight secondary ion mass spectrometry? Surface \& Interface Analysis. 2012;44(1):89-93.

20. Wilson RG. SIMS quantification in $\mathrm{Si}, \mathrm{GaAs}$, and diamond - an update. International Journal of Mass Spectrometry \& Ion Processes. 1995;143(94):43-49.

21. Wang Z, Liu B, Zhao EW, et al. Argon Cluster Sputtering Source for ToF-SIMS Depth Profiling of Insulating Materials: High Sputter Rate and Accurate Interfacial Information. Journal of the American Society for Mass Spectrometry. 2015;26(8):1-8.

22. Gin S, Abdelouas A, Criscenti $U$, et al. An international initiative on long-term behavior of high-level nuclear waste glass. Materials Today. 2013;16(6):243-248.

23. Collin $M$, Fournier $M$, Frugier $P$, et al. Structure of International Simple Glass and properties of passivating layer formed in circumneutral $\mathrm{pH}$ conditions. npj Materials Degradation. 2018;2(1):4. 